\title{
História da Psicologia Política: Heterogeneidade e institucionalização
}

\section{History of Political Psychology: Heterogeneity and institutionalization}

\section{Historia de la Psicología Política: Heterogeneidad e institucionalización}

\author{
Domenico Uhng Hur* \\ Universidade Federal de Goiás - UFG, Goiânia, Goiás, Brasil
}

\begin{abstract}
RESUMO
A Psicologia Política (PP) é um campo de conhecimentos heterogêneo e plural, ainda em consolidação. O objetivo deste artigo é conhecer os trabalhos que realizam um histórico sobre a PP, para discutir as diferentes narrativas dos autores da Europa, Estados Unidos e América Latina e redigir uma integração entre elas. Como método realizamos uma revisão bibliográfica sobre artigos, livros e capítulos que abordam a história da PP. Separamos a discussão em quatro tópicos: precursores da PP, fundação da PP, institucionalização da PP e a PP contemporânea na América Latina. Constatamos a constituição de um campo heterogêneo, marcado pelas diferenças regionais de como fazer pesquisas em PP. Percebemos que as narrativas históricas tendem a privilegiar os trabalhos de sua região e que 0 pensamento norte-americano não foi o protagonista para a criação da $\mathrm{PP}$, mas sim o europeu. Já na América Latina se assume uma perspectiva crítica e uma implicação com a transformação social.
\end{abstract}

Palavras-chave: história da psicologia, Psicologia Política, América Latina.

\begin{abstract}
Political Psychology (PP) is a heterogeneous and plural field of knowledge, still in consolidation. The purpose of this article is to know the works that make a history about PP, to discuss the different narratives of the authors of Europe, United States and Latin America, and write an integration between them. As a method, we carry out a bibliographical review on articles, books and chapters which refer to the history of PP. We divided the discussion into four sections: precursors of PP, foundation of PP, institutionalization of PP and PP in Latin America. We see the constitution of a heterogeneous field, marked by regional. We perceive that historical narratives tends to privilege the works of their region and that American thought was not the protagonist for the creation of PP, but the European. In Latin America, a critical perspective and an implication with social change is assumed.
\end{abstract}

Keywords: history of psychology, Political Psychology, Latin America. 


\begin{abstract}
RESUMEN
La Psicología Política (PP) es un campo de conocimientos heterogéneo y plural, aún en consolidación. El objetivo de este artículo es conocer los trabajos que realizan un histórico sobre la PP, para discutir las diferentes narrativas de los autores de Europa, Estados Unidos y Latinoamérica y redactar un intento de integración entre ellas. Como método realizamos una revisión bibliográfica sobre artículos, libros y capítulos que abordan la historia de la PP. Dividimos la discusión en cuatro apartados: precursores de la PP, fundación de la PP, institucionalización de la PP y la PP contemporánea en Latinoamérica. Constatamos la constitución de un campo heterogéneo, marcado por las diferencias regionales do cómo hacer las investigaciones en PP. Percibimos que las narrativas privilegian los trabajos de su región y que el pensamiento estadounidense no fue el protagonista para la creación de la $\mathrm{PP}$, pero si el europeo. En Latinoamérica se asume una perspectiva crítica e una implicación con el cambio social.
\end{abstract}

Palabras clave: historia de la psicología, Psicología Política, Latinoamérica.

Nada mais difícil do que a realização de um histórico de um campo de saberes ainda em consolidação. Redigi-lo significa ressaltar partes, deixar algumas de fora, ou mesmo desconhecer outras. Dessa forma, a reescrita da história pode parecer injusta, como resultado que é da inserção do pesquisador no campo, a partir de sua perspectiva histórica e regional. Conforme sabemos, toda narrativa histórica acaba sendo parcial, incompleta.

E é com essa sensação, lacunar, que nos deparamos com os históricos sobre a Psicologia Política (PP ${ }^{1}$ ) enquanto disciplina. A PP, tal como a Psicologia Social (Farr, 1998), tem um longo passado, mas considera-se que tem uma curta história, recente e em consolidação (Sabucedo, 1996; Stone \& Schaffner, 1988). São diversas as suas definições ${ }^{2}$, como a de Stone \& Schaffner (1988), que afirmam que "Political Psychology can be defined both as the 'influence of psychological processes on political behavior', and as the effect of a particular political systems on the thought, feelings, and motives of its members" (p. 30). Outra definição importante é a de Sabucedo (1996), que afirma que a PP "consiste en el estudio de las creencias, representaciones o sentido común que los ciudadanos tienen sobre la política, y los comportamientos de éstos que, ya por acción u omisión, traten de incidir o contribuyan al mantenimiento o cambio de un determinado orden socio-político" (p. 22).

Existem inúmeros trabalhos que traçam seu histórico. Alguns realizam uma história celebrativa, com os principais atores, datas e marcos. Não obstante, como pesquisadores do campo da PP, percebemos uma certa cisão nessas narrativas. Constatamos um certo viés geográfico. Parte significativa dos textos de autores do hemisfério norte desconhece, ou não cita, o desenvolvimento da PP do hemisfério sul, principalmente da América Latina, como por exemplo o verbete Political Psychology das italianas Sensales e Secco 
(2014) na Encyclopedia of Critical Psychology. Os norte-americanos redigem um histórico praticamente estadounidense, e os europeus adicionam o percurso do campo no velho continente, sendo raros os casos em que citam a PP na América Latina, como Sabucedo (1996) e Dorna (1998). Por sua vez os históricos redigidos por psicólogos políticos latino-americanos também não analisam de forma pormenorizada o desenvolvimento do campo no hemisfério norte, ou mesmo nos Estados Unidos (EUA), onde a International Society of Political Psychology (ISPP) foi criada.

Há assim uma divisão na qual coexistem duas formas de fazer PP que pouco têm contato: a vertente norte-americana e a vertente latinoamericana. Dessa forma o objetivo deste artigo é, a partir do estudo dos trabalhos que realizam um histórico sobre a Psicologia Política, discutir as diferentes narrativas dos hemisférios norte e sul e tentar construir uma integração entre elas. Como a história da PP é tratada nestes textos? Além dessa cisão, há outras singularidades na escrita de cada percurso histórico? Por que será que houve essa divisão?

Para responder a tais questões, realizamos uma revisão bibliográfica (Creswell, 2010) sobre artigos, livros e capítulos que abordam a história da PP. Buscamos artigos nas principais bases de dados virtuais ${ }^{3}$ e consultamos livros publicados sobre o tema, restringindonos aos textos escritos em português, espanhol, francês e inglês. Também consultamos os artigos publicados nas revistas de PP da França, Espanha, Argentina e Brasil. Os livros analisados referem-se a exemplares que temos em nossa biblioteca pessoal, bem como os da Biblioteca da Universidade de Santiago de Compostela, que possui um dos maiores acervos de títulos de PP, considerando-se as bibliotecas universitárias da Espanha e da AL ${ }^{4}$. Realizamos um mapeamento, uma cartografia (Passos, Kastrup, \& Escóssia, 2009), sobre as obras encontradas, bem como análise de conteúdo (Bardin, 1977). Neste sentido, fragmentamos os dados em unidades de registro, para depois agrupá-los em unidades de conteúdo, e finalmente, construir as categorias de análise (Vázquez, 1997). Ressalta-se que em nossa 'cartografia histórica', realizamos uma espécie de 'geografia', na qual percorremos diversos países, sobretudo do Ocidente. Assim, nosso interesse não foi o de realizar uma arqueologia, 'escavar a tumba do faraó', mas sim acompanhar os movimentos de deslocamentos, a 'deriva dos continentes' (Deleuze, 1993). Enfim, investigar os movimentos das narrativas da história.

O conteúdo encontrado nos textos é bastante heterogêneo, não havendo uma única história relatada. Para a discussão agrupamos os dados encontrados em quatro tópicos: precursores da PP; fundação da PP; institucionalização da PP e a PP contemporânea na AL. 


\section{Precursores da Psicologia Política}

Neste tópico citamos os autores que aparecem como as principais referências teóricas para o posterior surgimento da PP. Diferenciamos este momento da 'fundação da $\mathrm{PP}^{\prime}$, por entender que os 'precursores' não a instituíram e situam-se em outros campos de conhecimento, por mais que possa haver uma obra ou outra com o nome de PP. Essa divisão é distinta do histórico de Dorna (1998, 2006), que aglutina os autores de referência e os fundadores no mesmo grupo. Dorna, em seu minucioso histórico, afirma, inclusive, que o pensamento que referenciou a PP data de períodos antigos: parte da Grécia antiga, passa pelo Império Romano, até o período atual. Parisí (2007) também se refere à Grécia como alicerce da PP.

Nos textos analisados encontramos muitos autores que figuram como os principais pilares da PP. Há uma espécie de tendência geográfica para a produção histórica, na qual os norte-americanos privilegiam uma narrativa a partir dos personagens anglo-americanos, e os pesquisadores europeus realizam um histórico valorizando os autores de seu continente (Bryder, 1986; van Ginneken, 1988). Há também uma mistura em diversos textos com a história da Psicologia Social, que reflete a porosidade das fronteiras entre os dois campos. Para nosso trabalho agrupamos os autores que figuram como os pilares da PP em quatro países/regiões principais: França, Itália, Inglaterra e o bloco Alemanha/Áustria/Rússia.

A França aparece como um dos países mais citados na historiografia existente, especialmente por pesquisadores brasileiros (Rosa \& Silva, 2012; Sandoval, 1997). Aquele país foi um manancial de autores que são influentes até hoje, seja nas Ciências Sociais, seja nas Ciências Políticas e na Psicologia, como E. Durkheim (1858-1917), H. Taine (1828-1893), G. Tarde (1843-1904) e principalmente G. Le Bon (1841-1931) (Bryder, 1986; Dorna, 1998). Le Bon ocupa lugar emblemático como fundamento da PP pelos seus estudos sobre o comportamento primitivo das massas (1895) e também por obras sobre o socialismo, a defesa social e a própria PP. Mas também é alvo de polêmicas, devido a seu posicionamento conservador e eugenista, e por considerar que a atuação em coletivos sociais rebaixa 0 intelecto das pessoas ali presentes.

A Itália é o segundo país listado pelos historiadores da PP (Dorna, 1998; Silva, 2016; van Ginneken, 1988), mas que não assume tanta importância como a França. São citados pensadores, que, entre outras realizações, fundamentaram uma teoria das elites, tais como V. Pareto (1848-1923), G. Mosca (1858-1941) e R. Michels (18761936). Vale ressaltar as teorizações de Michels (1914) sobre o que denominou de 'oligarquização das minorias dirigentes'. Este é o fenômeno no qual lideranças de movimentos trabalhistas, pertencentes ao proletariado, ao negociar diretamente com as elites, 
passam a se identificar com elas, resultando numa espécie de 'aburguesamento'.

A Inglaterra é outro dos países citados como local de referência para a PP. W. McDougall (1871-1938) é recordado como um pensador que traz enunciado que se opõe ao de Le Bon sobre os grupos. Ao invés de focalizar o caráter regredido das massas, ressalta as produções coletivas do pequeno grupo. G. Wallas (1858-1932) e W. Trotter (1872-1939), este, cunhado do psicanalista E. Jones (1926-1993) -, também são citados como importantes precursores para a PP (van Ginneken, 1988; Dorna, 1998).

Fora do eixo dos países latinos e Inglaterra, agrupamos o bloco Alemanha/Áustria/Rússia, países que se situam mais ao leste na Europa. Figura como uma das principais regiões geográficas para a PP na análise dos historiadores norte-americanos e europeus (Bryder, 1986; Dorna, 1998; Lavine, 2004; van Ginneken, 1988). Dentre os pilares citamos S. Freud (1856-1939), K. Marx (1818-1883) e V. I. Lenin (1870-1924). Freud e seus estudos que articulam a psicanálise a processos sociais são muito citados na literatura de PP, principalmente sua teorização sobre o comportamento regredido das massas (1921), apoiada diretamente nos enunciados de Le Bon. van Ginneken (1988) afirma que alguns de seus discípulos também exercem influência na PP, tal como A. Adler (1870-1937). Vale ressaltar que por mais que no Brasil e na América Latina a psicanálise não tenha influenciado muito a PP, ela foi a principal corrente teórica para o $1^{\circ}$ momento da PP ocidental (Lavine, 2004).

O líder da Revolução Russa, V. I. Lenin, é citado pelo sueco T. Bryder (1986), em trabalho que investiga a constituição da PP na Europa. Foi a única citação que encontramos sobre ele em toda a bibliografia histórica da PP (exceto os textos que citam o capítulo de Bryder). "Lenin concerned himself with the problems of political consciousness. Lenin was interested in the question of how political behavior can be stimulated through experience and learning in context designed for collective action" (p. 437). Bryder (1986) contrapõe Lenin a Le Bon, discutindo como processos de conscientização podem surgir da ação coletiva, realizando dura crítica a Le Bon e aos estudos influenciados por ele.

Marx praticamente não é citado nos históricos da PP norte-americana, salvo raras exceções, quando autores como Alford (1993), ao discutir a Escola de Frankfurt, citam brevemente a teoria de Marx, ou o capítulo de Davies (1986), que coloca Freud e Marx como possíveis raízes da PP. Exceto esses casos não encontramos referência a Marx em históricos da PP, nem em Dorna (1998). Esse é um fato surpreendente, considerando que é um pensador que influenciou intensamente os pensadores alemães que fundam a PP, a posterior Psicologia Política Latino-americana (PPL), a Psicologia da Libertação de I. Martín-Baró e a Psicologia Crítica mundial. Neste sentido, devido 
sua importância, propomos aqui que K. Marx e V. I. Lenin sejam destacados como importantes precursores da PP, e principalmente da PPL.

Consideramos que estas são as principais regiões nas quais foram cimentadas as bases para a constituição da PP. Evidentemente não são as únicas. Por exemplo, na Espanha cita-se a importância de Ortega y Gasset (1883-1955) (Dorna, 1998), no Brasil autores como V. de Britto (1856-1924) e F. J. O. Vianna (1883-1951) (Silva, 2015), R. Salas Edwards (1870-1939) no Chile (Godoy \& Romero, 2018) etc.

\section{Fundação da Psicologia Política}

Para a maioria dos autores a fundação da PP ocorre em dois lugares: nos EUA e na Alemanha. Em realidade, a maior parte dos trabalhos históricos cita o cenário norte-americano, deixando o alemão em segundo plano. Entretanto, consideramos que não são histórias excludentes e inclusive ambas mantêm uma certa conexão.

A Alemanha foi lugar de pensadores que analisaram a sociedade a partir de saberes psicológicos e políticos, sobretudo pelos desafios que enfrentava com a ascensão do nazismo. Afirma-se que W. Reich (1897-1957), com sua psicologia das massas do fascismo (1933), está na base da PP alemã. Além de proporcionar importante reflexão psicopolítica ao analisar os fundamentos políticos e sexuais de adesão ao fascismo, Reich também criou o primeiro periódico que recebeu o nome de PP. "Meanwhile, Reich had spent some time in Scandinavia, where for a short time he edited the Journal of Political Psychology and Sexual economy (in German, 1934-1935)" (van Ginneken, 1988, p. 11). Sua obra influenciou outros autores de grande magnitude, como os que fizeram parte do Instituto de Pesquisas Sociais, conhecido como Escola de Frankfurt. "Under the growing menace of fascism and national socialism, the Frankfurt Institute of Social Research invited psychoanalysts such as Erich Fromm to participate in a research Project on authoritarianism and family life, a project greatly stimulated by the writings of Wilhelm Reich" (Bryder, 1986, p. 449). Neste sentido, M. Horkheimer (1895-1973) (1936) organizou o livro "Studien über Autorität und Familie", que contou com renomados autores que articulavam o marxismo à psicanálise nos estudos sobre a autoridade e temas correlatos, como $\mathrm{H}$. Marcuse (1898-1979) e E. Fromm (1900-1980). Este último posteriormente publicou o importante livro "Escape from freedom". Nele, Fromm (1941) discute a adesão ao autoritarismo, a submissão a um líder, como forma de escapar da incerteza, insegurança e impotência. Para aplacar o mal-estar, atua-se no que denomina uma estrutura similar ao masoquismo e se "Entrega su propio yo y renuncia a toda la fuerza y orgullo de su personalidad; pierde su integridad como 
individuo y se despoja de la libertad; pero gana una seguridad que no tenía y el orgullo de participar en el poder en el que se ha sumergido. También se asegura contra las torturas de la duda" (Fromm, 1941, p. 180). Seguindo a mesma tradição teórica, mas com sua singularidade e já nos EUA, o grande filósofo T. W. Adorno (1903-1969) fez parte da equipe de Berkeley e coordenou o mais importante estudo de PP da época, a pesquisa sobre "The Authoritarian Personality" (Adorno, Frenkel-Brunswick, Levinson \& Sanford, 1950), discutido adiante. E vale destacar que, em 1958, a Deutsche Gesellschaft für Psychologie, Associação Alemã de Psicologia, criou uma seção de Psicologia Política (Bryder, 1986).

Entretanto, Alemanha não era apenas Luzes contra a escuridão e crítica contra o autoritarismo. van Ginneken (1988) conta um fato obscuro. Apenas " $40 \%$ dos professores de psicologia e $15 \%$ dos membros de associações profissionais foram obrigados a sair da Alemanha" (p. 14) devido ao regime nazista. Afirma que entre os psicólogos havia muitos que apoiavam, identificavam-se, ou pouco se incomodavam com o nazifascismo. Cita importantes psicólogos da época que inclusive faziam apologia ao regime hitlerista: "The wellknown psychologist Poppelreuter, for instance, gave a series of lectures and wrote a brochure on political psychology ${ }^{5}$ (1932), hailing Hitler's Mein Kampf as its best example. The even better known psychologist Jaensch published a racist book, The Anti-Type" (p. 14). Dessa forma, o primeiro livro de PP na Alemanha não trazia uma crítica ao nazismo, mas sim sua exaltação.

Atravessando o Oceano Atlântico, grande parte dos autores (Davies, 1973; Deutsch, 1983; Lavine, 2004; Penna, 1995) traça a história oficial da fundação da PP. Esta ocorreu nos EUA, na qual os pensadores em Ciências Sociais da Universidade de Chicago tiveram papel fundamental tanto para a constituição da PP, como da Psicologia Social. A história celebrativa da PP situa como momento fundador o interesse de C. Merriam (1874-1953) na década de 1920 em articular os estudos psicológicos à Ciência política. No entanto, entendemos Merriam como um precursor, e seu discípulo H. Lasswell (1902-1978) como o efetivo fundador do campo no território estadunidense, devido à sua grande e pungente obra que criou uma nova tradição.

Algo interessante é que a tradição norte-americana de PP não floresceu isoladamente a partir do desenvolvimento das pesquisas e teorias dentro da Universidade de Chicago. Consideramos que ela só foi possível a partir do intercâmbio com as teorias europeias. Lasswell ganhou uma bolsa de estudos que permitiu que pesquisasse na Europa. Lá teve a oportunidade de estudar com E. Mayo (1880-1949) e conhecer e se aprofundar nas teorias psicanalíticas, principalmente na perspectiva de A. Adler. Também teve contato com psicanalistas famosos, como o próprio Adler, S. Ferenczi (1873-1933), T. Reik 
(1888-1969) etc., que inclusive são agradecidos no prefácio de seu livro fundador da PP norte-americana, "Psychopatology and Politics" (1930). Portanto, a PP estadounidense apenas surgiu com a importação de teorias europeias ao solo americano.

Nesta obra, Lasswell (1930) realiza uma espécie de psicanálise da política, ou melhor, uma psicanálise do ator político, numa perspectiva de uma PP mais psicológica e estabelecendo uma tipologia de ativistas. Sua tese principal é de que há um deslocamento de uma problemática privada para a ação política no espaço público. Assim "political movements derive their vitality from the displacement of private affect upon public objects..." (Stone \& Schaffner, 1988, p. 183). Para tratar desse deslocamento do psíquico ao político elabora uma equação simples: $\mathrm{p}\} \mathrm{d}\} \mathrm{r}=\mathrm{P}$, "en la que $p$ equivale a los motivos privados; $d$ designa el desplazamiento sobre un objeto público; $r$ la racionalización en función del interés público; $P$ el hombre político; y $\}$ equivale a 'transformado en'." (Lasswell, 1930 , p. 83). Ele mantém a tradição de estudos de Adler sobre a inferioridade, defendendo que o poder público tem como função psíquica superar problemas de auto-estima. Vale sublinhar que este livro não se chama Psicologia e Política, ou Psicologia da política, mas Psicopatologia e política. Talvez a lógica disciplinar da época, com ênfase normalizadora (Foucault, 1984), fez com que ressaltasse as condutas que podem ser consideradas psicopatológicas dos diversos atores políticos que analisa. Trata a contribuição do psicológico à política numa perspectiva de normalização, como modo de investigar a incidência do patológico, do desvio e do que foge da norma.

Outro marco fundante da PP norte-americana apenas foi possível com a elevada migração europeia de psicólogos, filósofos e cientistas sociais para os EUA devido ao perigo do nazifascismo e as vicissitudes da $2^{a}$ guerra mundial, tais como K. Lewin (1890-1947), M. Sherif (1906-1988), H. Marcuse, T. Adorno, E. Fromm, entre muitos outros. Tal migração não apenas consolidou formas de fazer a Psicologia Social com elevada influência europeia, difundindo por exemplo a Psicologia da Gestalt, como também alavancou a própria PP.

The Authoritarian Personality (Adorno et al., 1950) figura como um dos grandes marcos da PP, sendo muito relevante até para os dias atuais. Adorno se integra à equipe da Universidade de Berkeley, que já realizava pesquisas sobre o antissemitismo, e que foram impulsionadas pelo financiamento do Comitê Judeu americano (Sabucedo, 1985, 1996; Sanford, 1973). Buscava-se investigar traços psicossociais relacionados ao antissemitismo e às personalidades antidemocráticas, com uma problemática ética de evitar a constituição de novas lideranças autoritárias. Vale destacar que essa linha de estudos segue a tradição instaurada por Reich (1933) e que passa por Horkheimer (1936) e Fromm (1941). 
A pesquisa inovou do ponto de vista de método, adotando procedimentos qualitativos e quantitativos. Realizou-se entrevistas clínicas de enfoque psicanalítico e aplicação de testes projetivos de personalidade (como TAT e Rorschach). Com os dados acumulados, construiu-se escalas (antissemitismo, etnocentrismo, conservadorismo político, fascismo) como forma de ampliar a amostra a ser investigada, dando um tratamento estatístico aos dados. A partir dos resultados elencou-se distintas características da "síndrome da personalidade autoritária", como: convencionalismo, submissão e agressão autoritária, anti-intracepção, superstição e estereotipia, poder e dureza, destrutividade e cinismo, projeção e preocupação exagerada pelas questões sexuais (Sabucedo, 1996). Tal obra foi tão impactante para o campo que, nos primeiros seis anos de sua publicação, já havia 260 trabalhos que o citavam (Greenstein, 1973), seja como matéria de referência, de reformulação conceitual, ou como alvo de críticas, devido a uma suposta falta de rigor metodológico (Martin, 2001).

O campo da PP se desenvolveu de forma plural e heterogênea nos EUA, seja com os europeus que migraram ao país, ou com os próprios psicólogos norte-americanos. Além dos psicanalistas e teóricos críticos, van Ginneken (1988) ressalta os estudos de atitudes sociais e suas escalas de mensuração, citando autores como Thurstone (1887-1955), Likert (1903-1981), Bogardus (1882-1973) etc. Muitos estudos sobre atitudes foram direcionados à pesquisa do comportamento político e eleitoral, adquirindo relevância e difusão no país. Dessa forma, McGuire (1993) elenca três momentos nos estudos da PP norte-americana: 0 10, da Personalidade e Cultura (1940-1950), o 20, das atitudes políticas e comportamento eleitoral (1960-1970), e o 30 (1980- ...), da ideologia política. Por sua vez, Lavine (2004) realiza outra divisão, referente às ferramentas teóricas da PP. O 10 foi o estudo dos fenômenos políticos pela psicanálise, 0 20 das atitudes políticas via escalas e atualmente a utilização da Psicologia cognitiva.

Para uma análise mais detalhada do campo nos EUA, sugerimos a leitura do capítulo de Ward (2002) que, em seu histórico, faz uma grande lista das principais obras que influenciaram a consolidação da PP como disciplina de saber, desde o marco fundante, de Lasswell (1930) até a publicação do manual de Psicologia Política (Knutson, 1973). Porém, assume certo viés ao privilegiar as obras angloamericanas, ou dos investigadores imigrados, pouco citando autores europeus. No entanto, de modo diferente a van Ginneken (1988), as obras que cita não se misturam com a história da Psicologia Social, salvo raros casos. 


\section{Institucionalização da Psicologia Política}

A institucionalização da PP ocorre quando o campo cumpre alguns requisitos básicos para a constituição de uma disciplina, tal como Farr (1998) sugere: a oferta de cursos, a publicação de um manual que integre o conhecimento da área, a criação de uma associação e de um periódico acadêmico. Essa conjunção de fatores ocorreu na década de 1970 nos EUA, graças ao esforço de J. Knutson, que organizou o primeiro Handbook of Political Psychology, publicado em 1973. Nele, vários temas são abordados, como: personalidade e política, atitudes políticas, crenças políticas, socialização política, autoritarismo, anomia e alienação, liderança, agressão, política internacional e métodos de investigação. O manual expressa o campo heterogêneo da PP norte-americana, seja por questões teóricas e metodológicas, e o texto final, de autoria de F. Greenstein (1973), encoraja essa pluralidade ao campo, sugerindo que "let many flowers bloom". Knutson também foi protagonista na articulação da International Society of Political Psychology (ISPP). Primeiramente ela seria criada nos moldes da American Psychological Association e da American Political Science Association, mas, no debate entre os pesquisadores da sociedade, optou-se por assumir o perfil internacional. O primeiro congresso da ISPP ocorreu no mesmo ano em Nova Iorque (1978), e em 1979 foi criada a Revista Political Psychology. A ISPP possui mais de mil membros filiados de cerca de 55 países. Desde 1990 ministra o Summer Institute of Political Psychology, pelo qual já passaram mais de 500 estudantes (Ward, 2002).

Ressalta-se que houve a publicação de muitas coletâneas com o mesmo título "Political Psychology" nos últimos 25 anos nos EUA. Praticamente todas mantêm o mesmo estilo, com um apanhado das principais temáticas desenvolvidas na área. Após o Manual (Knutson, 1973), o grupo ligado à ISPP publicou Political Psychology (Hermann, 1986) e depois Oxford Handbook of Political Psychology (Sears, Huddy, \& Jarvis, 2002). Devido ao grande volume de livros de PP, no prefácio de Sears et al. (2002) chega-se ao ponto de afirmar porque essa compilação seria mais completa que o Political Psychology de Renshom e Duckitt (2000) - que prioriza uma PP transcultural - o Political Psychology de Monroe (2000) e o Thinking about Political Psychology de Kuklinski (2002), que são vistos como se restringindo às pesquisas dos diferentes autores. Entretanto, o livro de PP que teve maior difusão na atualidade não é nenhum destes citados, mas, sim, o Political Psychology de Jost e Sidanius (2004). Este livro é uma coletânea de textos clássicos de PP já publicados em revistas e livros, sendo uma espécie de um guia de leitura geral para a PP. Além desses há muitos outros títulos de livros de PP, como alguns livros introdutórios (Cottam et al., 2010; Houghton, 2009). 
A partir da pesquisa da literatura de PP norte-americana constata-se ao menos três questões. Primeiro, diferentemente do que é propagado pelo senso comum do campo na $A L$, as pesquisas em PP nos EUA não se restringem aos temas de comportamento eleitoral e persuasão política, não utilizam apenas métodos positivistas, quantitativos e experimentais e nem assumem somente uma posição política de neutralidade. Há uma diversidade de temas investigados, pesquisas qualitativas e de métodos mistos e também perspectivas críticas e politizadas.

Segundo, a PP norte-americana não criou uma tradição teórica apenas a partir da matriz positivista dos tradicionais estudos estadunidenses. Diferentemente da análise de Farr (1988) que, referenciado em G. Allport (1897-1967), afirma que, se as raízes da Psicologia Social estão no Ocidente, ela floresceu nos EUA, consideramos que a PP norteamericana, assim como a Psicologia Social, é diretamente resultante dos conhecimentos europeus articulados aos métodos científicos do território americano. Pois seja com seu teórico fundador, Lasswell, que realizou seu intercâmbio na Europa, tendo contato com renomados pensadores de diversos países, seja com a migração dos europeus para os EUA onde difundiram suas formas de pesquisar, pensar, e formaram alunos, como o próprio $M$. Deutsch (1983), percebe-se que não só as raízes da PP são do velho continente. No cruzamento entre tradições heterogêneas, inventou-se uma nova disciplina, ainda em consolidação, híbrida disciplinarmente, bem como geograficamente.

Terceiro, diferentemente do que é imaginado no Brasil, a consolidação da PP nos EUA não é tão intensa. Por exemplo, Ward (2002) afirma que em sua época apenas os estudantes 'corajosos' podiam seguir a formação em PP, devido às poucas possibilidades profissionais que havia para esse tipo de carreira. "For example, when I went on the job market in the early 1980s, the only institution specifically seeking to hire political psychologists was the CIA" ( $p$. 64). Esse exemplo surpreende, pois o estabelecimento que empregava psicólogos políticos era a Central Intelligence Agency (CIA) atrelando assim a PP a práticas policialescas e de captura do Estado (Deleuze \& Guattari, 1997). E Jost (2017), ao prefaciar o livro do Grupo de PP de Córdoba, Argentina (Brussino, 2017), também surpreende ao afirmar que "there are now far more university students taking political psychology courses every year in Buenos Aires than in New York, Chicago, Paris, Rome, or Berlin" (p. 10). Independentemente se está correto ou não em sua afirmação, de que em Buenos Aires estuda-se mais PP do que nessas grandes cidades, pode-se inferir que a PP não é tão estudada assim nos EUA, visto que há dois grupos de pesquisa de PP em Buenos Aires, e apenas quatro em todo território argentino (Brussino, Rabbia, \& Imhoff, 2010). 
Também vale destacar que há diversos trabalhos que abordam a PP em outras localidades, como na Espanha (Garzón, 1993; Moya \& Morales, 1988), Bélgica (Bryder, 1986), Ásia (Dorna, 1998; Pye, 1986;), Canadá (Nesbitt-Larking, 2004), AL (Montero, 1987b) etc. Mas, como dissemos na Introdução deste texto, aqui só vamos nos deter nestes já trabalhados e na América Latina, nosso item seguinte.

\section{A Psicologia Política na América Latina}

A PPL tem uma gestação tardia, embora já existissem estudos que articulassem Psicologia e política ao longo do século XX. Sua constituição não ocorreu por influência direta dos estudos da PP norte-americana, visto que poucos são citados em seus históricos (Brussino, 2017; Montero, 1987b; Silva, 2015.). A PPL constitui-se como uma resposta à crise da Psicologia Social (Camino \& Menandro, 1996), durante a qual houve um descontentamento com o caráter supostamente neutro da disciplina, devido ao contexto social efervescente das décadas de 1960 e 1970. O cenário sócio-político latino-americano estava marcado por ditaduras civis-militares, oligarquias repressivas ocupando o poder do Estado, miséria e contradições sociais agudas. Dessa forma a PPL se constituiu de forma autônoma em seu continente, muito marcada pela resistência ao contexto em que se vivia e a utopia de produção de novas práticas emancipadoras.

O marco fundador do campo foi a publicação do livro Psicología Política Latinoamericana (Montero, 1987a), do qual participaram grandes nomes de referência da Psicologia Política e Social do continente até os dias de hoje. Na obra há uma crítica à Psicologia instituída, vista como positivista, a-histórica, individualista, e a assunção de um compromisso ético-político nas investigações e intervenções em PP na AL. Os principais temas trabalhados nessa primeira coletânea foram: repressão política, consciência e alienação, ideologia e política, a ação do psicólogo nos sindicatos, conflito e paz. Nela, há o magistral capítulo que cartografa uma das condições assumidas pelo latino-americano: o fatalismo (Martín-Baró, 1987). O espanhol radicado em El Salvador, Martín-Baró (1942-1989), tornouse um dos principais emblemas da PPL, com uma produção exuberante. Seu cruel assassinato devido ao caráter crítico e denunciativo de seus escritos e discursos cortou esta contribuição. Para ele a PPL não deveria realizar somente uma psicologia da política, senão articulá-la com uma análise das próprias políticas da psicologia, ou seja, investigar que tipos de configurações de forças e posicionamentos político-sociais os enunciados e práticas da psicologia assumem. Nesse sentido, Martín-Baró (1991) ressalta a importância do engajamento e do compromisso ético-político do 
psicólogo em intervir em direção à transformação social, distanciando-se de qualquer discurso de neutralidade. Nessa mesma perspectiva, L. Camino (2005) aponta que seu grupo de pesquisa era de pesquisadores e militantes ao mesmo tempo, o que o levou a buscar novas referências teóricas e não ficar limitado à PP norteamericana. Devido a esse posicionamento comprometido da PPL, e que ressoou nas produções no continente, considera-se que houve uma virada política da PP na AL (Hur, Sabucedo, \& Alzate, 2018).

Evidentemente a politização e a implicação da PP é um tema polêmico e em debate. Hermann (1986) realiza uma cisão entre engajamento e perspectiva analítica: "And for many of those in political psychology, there is a tension between wanting to make a difference and maintaining an analytical perspective" (p. 2), como se quem assumisse uma implicação política possivelmente perderia a perspectiva analítica. Nessa oposição, transparece claramente a ideologia da neutralidade científica. Mas Martín-Baró se contrapõe a esse tipo de cisão entre teoria e política, mantendo seu rigor acadêmico articulado ao compromisso com as minorias. A utopia da neutralidade científica é inclusive criticada por Montero (2015), a única presidente latino-americana da história da ISPP. "Sometimes, even important journals of political psychology have tried to assume a 'neutral' position, rejecting the publication of articles related to dictatorships, totalitarian governments, the segregation of certain ethnic groups, or anti-capitalist criticism" (p. 139). Montero critica, sem nomear, o periódico da ISPP, visto que as revistas de PP da França, Espanha, Brasil e Argentina costumam publicar estes temas. Com a constituição do campo, na década de 1990 foram publicados muitos livros de PP na AL (D'adamo, García Beadoux, \& Montero, 1995; Camino \& Menandro, 1996; Camino, Lhullier, \& Sandoval, 1997; Montero, 1991; Juárez et al., 1991; Mota, 1990, 1999; Penna, 1995; Oblitas \& Rodríguez, 1999). Em 2001 e 2002 foram criadas, respectivamente, a Revista de Psicologia Política (Brasil) e a Revista Electrónica de Psicología Política (Argentina). Todavia, o Brasil é o único país do continente que possui uma associação nacional, a Associação Brasileira de Psicologia Política, e congressos regulares de PP desde 2000.

Os textos históricos consideram que a PPL tem como singularidade uma forte implicação política com as minorias sociais e os processos de transformação social (Obando, 2016; Rodriguez, 2003). Neste sentido, trabalha com temas relacionados à participação política de movimentos e minorias sociais, como o movimento dos trabalhadores rurais, de gênero e LGBT, de minorias étnico-raciais etc. No Brasil, a atuação do psicólogo nas diversas políticas públicas também é tema bastante explorado (Hur \& Sabucedo, 2018). Dessa forma, constituiuse na AL uma PP mais sociológica do que psicológica, que assume um caráter interdisciplinar com outros campos de conhecimento, como as 
Ciências Sociais, a História e a Filosofia, ou seja, uma disciplina na encruzilhada (Montero \& Dorna, 1993). Do ponto de vista dos referenciais teóricos, constata-se que há dois principais momentos: primeiramente uma perspectiva mais crítica, e posteriormente a adoção do construcionismo social.

Os estudos e publicações em PP na AL vêm crescendo intensamente (Polo et al., 2014). Uma expressão desse crescimento foi a criação em 2011 da Asociación Ibero-Latinoamericana de Psicología Política (AILPP) no Congresso da Sociedade Interamericana de Psicologia (SIP) em Medelín/Colômbia (Brussino, 2017). A AILPP congrega pesquisadores de países da AL e Portugal e Espanha, e organizou 4 congressos. O $1^{\circ}$ ocorreu em Lima/Peru (2012), o $2^{\circ}$ na Cidade de México (2014), o $3^{\circ}$ na cidade de Cali/Colômbia (2016), o $4^{\circ}$ em Valparaíso/Chile (2018) e o $5^{\circ}$ Congresso será em 2020 em Buenos Aires/Argentina.

A constituição da AILPP reflete o movimento de institucionalização do campo no continente. Além de promover a constituição de redes entre os pesquisadores, contribuiu para a organização de números temáticos sobre a PP em seus países, como por exemplo, o dossiê da Revista Psicologia Política (Brasil) que reuniu artigos que traçam o histórico da PP na Venezuela, Colômbia, México, Brasil, Peru e Chile. A proposta é que as revistas de PP do Brasil e da Argentina organizem periodicamente números temáticos da AILPP, que tenha participação ampla de pesquisadores latino-americanos. A criação dessa associação internacional também estimulou a produção local em cada país, com a publicação de livros de PP, como na Argentina (Brussino, 2017), Colômbia (Obando, 2016) e Brasil (Almeida, Silva, \& Corrêa, 2012; Hur \& Lacerda Jr., 2016a, 2016b; Sandoval et al., 2014; Silva \& Corrêa, 2015). Consideramos que um dos desafios deste momento é a produção de pesquisas e publicações coletivas que contem com pesquisadores de diversos países, bem como uma agenda que articule atividades a médio e longo prazo. Provavelmente esta articulação possibilitará a consolidação da PPL como um campo de conhecimento singular e implicado socialmente.

\section{Considerações finais}

Neste artigo foi realizada uma discussão sobre a história da PP enquanto um campo de saberes em consolidação. Foram apresentados livros, capítulos e artigos que narram essa história. Constata-se que as narrativas são realizadas a partir de suas distintas perspectivas geográficas, seja da Europa, EUA, ou AL. A maioria narra uma história celebrativa, com seus principais atores, obras fundantes e datas. Todavia, buscamos traçar uma cartografia que 
marcasse os movimentos, deslocamentos e consolidação na história da PP, abrangendo as três regiões.

Diferenciamos os autores que foram os pilares, as referências da PP, daqueles considerados como seus fundadores. Os precursores do campo situam-se na Europa, principalmente na França, Inglaterra, Itália e Alemanha/Áustria/Rússia e são de diversas áreas do conhecimento e tradições teóricas. Devido à sua importância para o campo, propomos neste artigo que Marx e Lenin figurem entre seus precursores.

Consideramos que os fundadores da PP são os que efetivamente criaram esta disciplina. Situam-se em dois países: EUA e Alemanha. Grande parte das narrativas marca a importância dos EUA para a constituição do campo, seja devido à obra de Lasswell, ou pela institucionalização da disciplina na década de 1970. Entretanto, defendemos que o pensamento norte-americano não foi 0 protagonista para a criação da PP, mas sim o europeu. Seja pela migração de pensadores europeus, principalmente alemães, preocupados com a problemática do fascismo e que constituíram a Psicologia Social e Política nos EUA; seja pela perspectiva de análise que Lasswell assumiu em suas obras seminais, diretamente influenciada pela psicanálise de Freud e de Adler; ou, ainda, pela importância do pensamento europeu que serviu de alicerce às teorizações da PP e da PPL. Vale citar que posteriormente 0 desenvolvimento do campo da PP nos EUA foi marcado por uma heterogeneidade na qual coexistem, hoje, perspectivas mais 'neutras', positivistas, com outras mais críticas.

$\mathrm{Na} \mathrm{AL}$ as narrativas históricas marcam os principais pontos de fundação da disciplina e principalmente a singularidade do campo no continente, que assume uma perspectiva crítica, um engajamento político e defende a transformação social e potencialização das minorias sociais. Citam mais a produção europeia do que a norteamericana, expressando uma espécie de ruptura da transmissão da $\mathrm{PP}$ dos EUA à AL. Constata-se também que os países do hemisfério sul buscam conhecer a literatura norte-americana e europeia, mas o movimento contrário é raro. Seja por barreiras linguísticas, ou pelo desinteresse ao que se produz na $A \mathrm{~L}$, norte-americanos e europeus raramente citam a produção de PP das 'periferias' do planeta.

Portanto, percebe-se a constituição de um campo heterogêneo, diverso, marcado pelas diferenças regionais de como fazer pesquisas na PP. Ainda não se constitui como um campo consolidado, apresentando uma grande porosidade com a Psicologia Social, e principalmente com uma Psicologia Social crítica e politizada. Esperase assim que esse texto possa contribuir como um alicerce para a reflexão no campo, para que os pesquisadores da área possam produzir novos enunciados que tornem a disciplina mais consistente e consolidada. 


\section{Referências}

Adorno, T. W., Frenkel-Brunswick, E., Levinson, D. \& Sanford, N. (1950). Personalidad autoritaria. Buenos Aires: Proyección.

Alford, C. F. (1993). Introduction to the Special Issue on Political Psychology and Political Theory. Political Psychology, 14(2), 199-208. Recuperado de www.jstor.org/stable/3791408

Almeida, M. A. B., Silva, A. S., \& Corrêa, F. (2012). Psicologia Política: Debates e embates de um campo interdisciplinar. São Paulo: Edições EACH.

Bardin, L. (1977). Análise de conteúdo. Lisboa: Edições 70.

Brussino, S., Rabbia, H., \& Imhoff, D. (2010). Psicología política en Argentina: Un recorrido por la historia de una disciplina emergente. Revista Psicologia Política, 10(20), 199-213. Recuperado de http://pepsic.bvsalud.org/pdf/rpp/v10n20/v10n20a02.pdf

Brussino, S. (2017). Políticamente: Contribuciones desde la Psicología Política en Argentina. Buenos Aires: CONICET.

Bryder, T. (1986). Political Psychology in Western Europe. In M. Hermann (Org.), Political Psychology: Contemporary Problems and issues (pp. 434-466). San Francisco: Jossey-Bass.

Camino, L., \& Menandro, P. R. (1996). A sociedade na perspectiva da Psicologia: Questões teóricas e metodológicas. Rio de Janeiro: Coletâneas da ANPEPP, 1 (13).

Camino, L., Lhullier, L., \& Sandoval, S. (1997). Estudos sobre comportamento político: Teoria e pesquisa. Florianópolis: Letras contemporâneas.

Cottam, M. L., Dietz-Uhler, B., Mastors, E., \& Preston, T. (2010). Introduction to Political Psychology. New York: Psychology Press.

Creswell, J. W. (2010). Projeto de pesquisa: Métodos qualitativo, quantitativo e misto. Porto Alegre: Artmed.

D'Adamo, O., García Beaudoux, V., \& Montero, M. (1995). Psicología de la acción política. Buenos Aires: Paidós.

Davies, J. C. (1973). Where from and Where to? In J. Knutson (Org.), Handbook of Political Psychology (pp. 1-27). San Francisco: Jossey Bass.

Davies, J. C. (1986). Roots of political behavior. In M. Hermann (Org.), Political Psychology: Contemporary Problems and issues (pp. 39-61). San Francisco: Jossey-Bass.

Deleuze, G. (1993). Crítica e clínica. São Paulo: 34.

Deleuze, G., \& Guattari, F. (1997). Mil Platôs, 5. São Paulo: 34.

Deutsch, M. (1983). ¿Qué es la Psicología Política? Revista Internacional de Ciencias Sociales, 96, 239-256.

Dorna, A. (1998). Fondements de la psychologie politique. Paris: Presses universitaires de France. 
Dorna, A. (2006). Pour une psychologie politique française. Paris: Press Éditions.

Farr, R. M. (1998). As raízes da psicologia social moderna. Petrópolis: Vozes.

Foucault, M. (1984). Vigiar e punir. Petrópolis: Vozes.

Fromm, E. (1941). El miedo a la libertad. Buenos Aires: Paidós, 1981. Garzón, A. (1993). Psicología Política en España. Boletín de Psicología, 39, 35-65. Recuperado de https://www.uv.es/garzon/adela/publicaciones/Psicologia\%20P olitica\%20en\%20Espana.pdf

Godoy, I., \& Romero, J. C. (2018). El origen temprano de la psicología política chilena. Interciencia: Revista de ciencia y tecnología de América, 43 (6), 455-460. Recuperado de https://www.interciencia.net/wp-content/uploads/2018/06/455GODOY-43_6.pdf

Greenstein, F. (1973). Political Psychology: A pluralistic universe. In J. Knutson (Org.), Handbook of Political Psychology (pp. 438470). San Francisco: Jossey Bass.

Hermann, M. (1986). Political Psychology: Contemporary Problems and issues. San Francisco: Jossey-Bass.

Horkheimer, M. (1936). Studien über Autorität und Familie. Schriften des Instituts für Sozialforschung, 1963.

Houghton, D. P. (2009). Political Psychology: Situations, individuals and cases ( $2^{\mathrm{a}}$ ed). New York: Routledge.

Hur, D. U., \& Lacerda Júnior, F. (2016a). Psicologia Política Crítica: Insurgências na América Latina. Campinas: Alínea.

Hur, D. U., \& Lacerda Júnior, F. (2016b). Psicologia, políticas e movimentos sociais. Petrópolis: Vozes.

Hur, D. U., Sabucedo, J. M., \& Alzate, M. (2018). El giro político de la Psicología Política Latinoamericana: Crítica, rol social y proyecto ético-político. Revista Electrónica De Psicología Política, 41, 130. Recuperado de http://www.psicopol.unsl.edu.ar/Anio16Numero41-125-Diciembre2018-Articulo1.pdf

Hur, D. U., \& Sabucedo, J. M. (2018). Psicología y política en Brasil: Psicología politizada o Psicología política? Revista de Investigación Psicológica, 19(1), 159-179.

Jost, J., \& Sidanius, J. (2004). Political Psychology. New York: Psychology Press.

Jost, J. (2017). Some reflections on the political mind: A prologue. In S. Brussino (Org.), Políticamente: Contribuciones desde la Psicología Política en Argentina. Buenos Aires: CONICET.

Juárez, J., Acosta, M.T., Uribe, J., González, M., Meza, H., Rodríguez, O., \& Solis, M.S. (1991). Ensayos de Psicología Política en México. México, DF: UNAM.

Knutson, J. (1973). Handbook of Political Psychology. San Francisco: Jossey Bass. 
Kuklinski, J. (2002). Thinking about Political Psychology. Cambridge: Cambridge University Press.

Lasswell, H. (1930). Psicopatología y política. Buenos Aires: Paidós, 1963.

Lavine, H. (2010). Political Psychology. London: Sage.

Le Bon, G. (1895). Psicología de las masas. Madrid: Morata.

Magaña, I., Dorna, A., \& Torres, I. (2016). Contribuciones a la Psicología Política en América Latina: Contextos y escenarios actuales. Santiago: RIL.

Martin, J. L. (2001). The authoritarian personality, 50 years later: What lessons are there for political psychology? Political Psychology, 22(1), 1-26. https://doi.org/10.1111/0162895X.00223

Martín-Baró, I. (1987). El latino indolente. Carácter ideológico del fatalismo latinoamericano. In M. Montero (Org.), Psicología Política Latinoamericana (pp. 135-162). Caracas: Panapo.

Martín-Baró, I. (1991). Métodos en Psicología Política. In M. Montero (org.), Acción y discurso: Problemas de psicología política en América Latina (pp. 39-58). Caracas: Eduven.

McGuire, W. J. (1993). The Poly-Psy Relationship: Three Phases of a Long Affair. In S. Iyengar \& W. McGuire, W. (Orgs.), Explorations in Political Psychology (pp. 9-35). Durham: Duke University Press.

Michels, R. (1914). Sociologia dos Partidos Políticos. Brasília: UNB, 1982.

Monroe, K. P. (2002). Political Psychology. New Jersey: Lawrence Erlbaum Associates.

Montero, M. (1987a). Psicología Política Latinoamericana. Caracas: Panapo.

Montero, M. (1987b). La Psicología Política en América Latina: 19561986. In M. Montero (Org.), Psicología Política Latinoamericana (pp. 15-66). Caracas: Panapo.

Montero, M. (1991). Acción y discurso: Problemas de psicología política en América Latina. Caracas: Eduven.

Montero, M. (2015). Political Psychology: Critical approaches to power. In I. Parker (Org.), Handbook of Critical Psychology (pp. 137-144). London: Routledege.

Montero, M., \& Dorna, A. (1993). La psicología política: Una disciplina en la encrucijada. Revista Latinoamericana de Psicología, 25(1), 7-15. Recuperado de https://www.redalyc.org/articulo.oa?id $=805 / 80525101$

Mota, G. (1990). Cuestiones en Psicología Política Mexicana. México, CRIM-UNAM.

Mota, G. (1999). Psicología Política del Nuevo Siglo: Una Ventana a la Ciudadanía. México: Somepso-SEP. 
Moya, M., \& Morales, J. F. (1988). Panorama histórico de la Psicología Política. In J. Seoane \& A. Rodriguez (Orgs.), Psicología Política (pp. 36-75). Madrid: Pirámide.

Nesbitt-Larking, P. (2004). Political Psychology in Canada. Political Psychology, 25(1), 97-114. https://doi.org/10.1111/j.14679221.2004.00358.x

Obando, O. L. (2016). Psicología Política sobre la participación de jóvenes desvinculados y desmovilizados del conflicto armado colombiano. Cali: Univalle.

Oblitas, L. A., \& Rodríguez, A. (1999). Psicología Política. Ciudad de México, DF: Plaza y Valdés.

Parisí, E. R. (2007). Psicología política y otros temas de psicología. Bs As: Ed. Cooperativas.

Passos, E., Kastrup, V., \& Escossia, L. (2009). Pistas do método da cartografia. Porto Alegre: Sulina.

Penna, A. G. (1995). Introdução à Psicologia Política. Rio de Janeiro: Imago.

Polo, L., Godoy, J. C., Imhoff, D., \& Brussino, S. (2014). Following the tracks of an emerging area: Bibliometric analysis of Latin American Political Psychology in the 2000-2010 period. Universitas Psychologica, 13(5), 2047-2057. Recuperado de http://www.scielo.org.co/pdf/rups/v13nspe5/v13nspe5a31.pdf

Pye, L. W. (1986). Political Psychology in Asia. In M. Hermann (Org.), Political Psychology: Contemporary Problems and issues (pp. 467-486). San Francisco: Jossey-Bass.

Reich, W. (1933). Psicologia de massas do fascismo. São Paulo: Martins Fontes, 1988.

Renshon, S. A., \& Duckitt, J. (2000). Political Psychology: Cultural and Crosscultural Foundations. Nova Iorque: New York University Press.

Rodríguez, A. (2003). Actualidad e historia de la psicología política latinoamericana. Les cahiers psychologie politique, 3. Recuperado de http://lodel.irevues. inist.fr/cahierspsychologiepolitique/index.ph p?id $=1587$

Rosa, L., \& Silva, A. S. (2012). A Psicologia Política: Um breve olhar sobre as Américas. In M. A. B. Almeida, A. S. Silva \& F. Corrêa, F. (Orgs.), Psicologia Política: Debates e embates de um campo interdisciplinar (pp. 9-36). São Paulo: Edições EACH.

Sabucedo, J. M. (1985). Autoritarismo y actitudes socio-políticas. Santiago de Compostela: Obradoiro de encuadernación.

Sabucedo, J. M. (1996). Psicología Política. Madrid: Síntesis.

Sandoval, S. A. M., Hur, D. U., \& Dantas, B. S. A. (2014). Psicologia Política: Temas atuais de investigação. Campinas, SP: Editora Alínea. 
Sears, D. O., Huddy, L., \& Jervis, R. (2002). Oxford Handbook of Political Psychology. Nova Iorque: Oxford University Press.

Sensales G., \& Secco A. D. (2014). Political Psychology. In T Teo (Org.), Encyclopedia of Critical Psychology (pp. 1419-1425). New York, NY: Springer.

Silva, A. S. (2012). A Psicologia Política no Brasil: Lembranças e percursos sobre a constituição de um campo interdisciplinar. Revista Psicologia Política, 12(25), 409-426. Recuperado de http://pepsic.bvsalud.org/pdf/rpp/v12n25/v12n25a04.pdf

Silva, A. S., \& Corrêa, F. (2015). No interstício das disciplinaridades: A Psicologia Política. Curitiba: Prismas.

Silva, A. S. (2016). Tarde, Sighele, Pareto, Mosca, Michels e Ortega y Gasset e a Psicologia Política nascente: Notas historiográficas de um campo interdisciplinar. In I. Magaña; A. Dorna \& I. Torres (Orgs.), Contribuciones a la Psicología Política en América Latina: Contextos y escenarios actuales (pp. 23-52). Santiago: RIL.

Stone, W. F. \& Schaffner, P. E. (1988). The Psychology of politics. New York: Springer-Verlag.

Torres, A. R. R., Lima, M. E. O. \& Costa, J. B. (2005). A Psicologia Política na perspectiva psicossociológica: $O$ estudo das atividades políticas. Goiânia: Ed. UCG.

van Ginneken, J. (1988). Outline of a Cultural History of Political Psychology. In. W. F. Stone, \& P. E. Schaffner (Orgs.), The Psychology of politics (pp. 3-22). $2^{\text {a }}$ ed. New York: SpringerVerlag.

Vázquez, F. (1997). El dispositiu d'anàlisi de dades: I'Anàlisi de contingut temàtic/categorial. Investigació $i$ Coneixement Psicosocial. Mimeografado.

Ward, D. (2002). Political Psychology: Origins and development. In K. R. Monroe (Org.), Political Psychology (pp. 61-78). New Jersey: Lawrence Erlbaum Associates.

\section{Endereço para correspondência \\ Domenico Uhng Hur}

Universidade Federal de Goiás

Faculdade de Educação

R. 235, s/no. Setor Leste Universitário, CEP 74605-050, Goiânia - GO, Brasil

Endereço eletrônico: domenico@ufg.br

Recebido em: 13/06/2019

Reformulado em: $12 / 08 / 2019$

Aceito em: $14 / 08 / 2019$

\section{Notas}

* Professor da UFG. Psicólogo, mestre e doutor em Psicologia Social (USP), com estágio doutoral (UAB) e pós-doutoral (USC/Espanha). Bolsista PQ-2/CNPq. 
${ }^{1}$ Neste artigo utilizamos a sigla PP para referir-nos à Psicologia Política, PPL à Psicologia Política latino-americana, EUA para Estados Unidos e AL à América Latina.

2 Ressaltamos que neste trabalho não focalizamos as diferentes definições do campo, tarefa para futura pesquisa, mas somente seu histórico.

${ }^{3}$ A busca nas bases de dados foi realizada entre 13 de maio e 5 de junho de 2019.

${ }^{4}$ Salientamos uma limitação deste artigo, pois não conseguimos consultar todas as publicações que versam sobre a história da PP, seja pelo fato de haver edições esgotadas de alguns livros, que não são encontrados nem em sebos, ou cobrança excessiva de alguns portais virtuais para o acesso de alguns artigos. Entretanto, consideramos que a não totalização de consulta a todas as obras publicadas não constituiu um prejuízo à reflexão aqui empreendida. Também vale destacar que, por questões de limites de extensão deste texto, não citamos todos os trabalhos encontrados.

${ }^{5}$ Poppelreuter, A. (1932). Political psychology. Lagensalza: Beyer \& Mann.

Este artigo de revista Estudos e Pesquisas em Psicologia é licenciado sob uma Licença Creative Commons Atribuição-Não Comercial 3.0 Não Adaptada. 